\title{
CONVEXITY OF BẺZIER NETS ON SUB-TRIANGLES
}

John A. Gregory and Jianwei Zhou

With minor revisions, November 1990.

To appear in CAGD. 


\title{
Convexity of Bẻzier Nets on Sub-triangles
}

\author{
by \\ John A. Gregory and Jianwei Zhou \\ Department of Mathematics and Statistics, Brunei University, \\ Uxbridge, UB8 3PH, England
}

\begin{abstract}
This note generalizes a result of Goodman[3], where it is shown that the convexity of Bèzier nets defined on a base triangle is preserved on sub-triangles obtained from a mid-point subdivision process. Here we show that the convexity of Bèzier nets is preserved on and only on sub-triangles that are "parallel" to the base triangle.
\end{abstract}

\section{Introduction}

Let $\mathrm{T}$ be a triangle, called the base triangle (see [1]), with vertices $\mathbf{V}_{\mathbf{1}}, \mathbf{V}_{\mathbf{2}} \mathbf{a n d} \mathbf{V}_{\mathbf{3}}$. (Here, and elsewhere in the paper, we assume that triangles are non-degenerate, that is, their vertices are not colinear.) Then each point $\mathrm{P}$ of the plane determined by $\mathbf{V}_{\mathbf{1}}, \mathbf{V}_{\mathbf{2}} \mathbf{a n d} \mathbf{V}_{\mathbf{3}}$.can be represented by its barycentric coordinates $(\mathrm{u}, \mathrm{v}, \mathrm{w})$ with respect to the base triangle $\mathrm{T}$ as

$$
\mathrm{P}=\mathrm{uV} \mathrm{V}_{1}+\mathrm{vV}_{2}+\mathrm{wV}_{3}, \mathrm{u}+\mathrm{v}+\mathrm{w}=1
$$

Denote $f_{n}$ as a set of $(n+1)(n+2) / 2$ values

$$
f_{n}=\left\{f_{i j k} \in R \mid i+j+k=n \quad i \geq 0, j \geq 0, k \geq 0,\right\} .
$$


The Bernstein polynomial of $f_{n}$ over $T$ is then given by

$$
B\left(f_{n} ; u, v, w\right)=\sum_{i+j+k=n} f_{i j k} B_{i j k}^{n}(u, v, w)
$$

Where

$$
B_{i j k}^{n}(u, v, w)=\frac{n !}{i ! j ! k !} u^{i} v^{j} w^{k}
$$

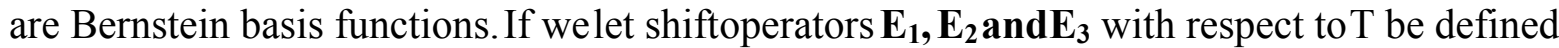
by

$$
E_{1} f_{i j k}=f_{i+1, j, k}, \quad E_{2} f_{i j k}=f_{i, j+1, k}, \quad E_{3} f_{i j k}=f_{i, j, k+1},
$$

then the Bernstein polynomial can be represented symbolically as

$$
\mathrm{B}\left(\mathrm{f}_{\mathrm{n}} ; \mathrm{u}, \mathrm{v}, \mathrm{w}\right)=\left(\mathrm{uE} \mathrm{E}_{1}+\mathrm{vE}_{2}+\mathrm{wE}_{3}\right)^{\mathrm{n}} \mathrm{f}_{000}
$$

Now we consider $(n+1)(n+2) / 2$ points of $T$ with barycentric coordinates $(i / n, j / n, k / n)$, namely,

$$
\mathrm{P}_{\mathrm{ijk}}=(\mathrm{i} / \mathrm{n}) \mathrm{V}_{1}+(\mathrm{j} / \mathrm{n}) \mathrm{V}_{2}+(\mathrm{k} / \mathrm{n}) \mathrm{V}_{3}, \mathrm{i}+\mathrm{j}+\mathrm{k}=\mathrm{n} .
$$

Connecting

$$
P_{i+1, j, k}, P_{i, j+1, k}, P_{i, j, k+1},
$$

we obtain a triangle, denoted $\mathrm{U}_{\mathrm{ijk}}$ for $\mathrm{i}+\mathrm{j}+\mathrm{k}=\mathrm{n}-1$. Similarly, a triangle $\mathrm{W}_{\mathrm{ijk}}$ is obtained for $\mathrm{i}+\mathrm{j}+\mathrm{k}=\mathrm{n}+1$ with

$$
P_{i-1, j, k}, P_{i, j-1, k}, P_{i, j, k-1}
$$

as its vertices. A piecewise linear function $\mathrm{L}\left(\mathrm{f}_{\mathrm{n}} ; \mathrm{u}, \mathrm{v}, \mathrm{w}\right)$, or $\mathrm{L}\left(\mathrm{f}_{\mathrm{n}}\right)$ for short, is defined on $\mathrm{T}$ such that it satisfies

$$
L\left(f_{n} ; P_{i j k}\right)=f_{i j k}, i+j+k=n,
$$

and is linear on each triangle $\mathrm{U}_{\mathrm{ijk}}$ or $\mathrm{W}_{\mathrm{ijk}}$. We call $\mathrm{L}\left(\mathrm{f}_{\mathrm{n}} ; \mathrm{u}, \mathrm{v}, \mathrm{w}\right)$ the Bèzier net of $\mathrm{f}_{\mathrm{n}}$.

The approximation theory of Bernstein polynomials and their applications inCAGD, Computer-aided Geometric Design, indicate that the Bėzier net $L\left(f_{n}\right)$ is closely related to $\mathrm{B}\left(\mathrm{f}_{\mathrm{n}} ; \mathrm{u}, \mathrm{v}, \mathrm{w}\right)$ and reflects certain features of $\mathrm{B}\left(\mathrm{f}_{\mathrm{n}} ; \mathrm{u}, \mathrm{v}, \mathrm{w}\right)$. As this note is concerned with the convexity, we state the following results (see $[1,2])$ : 
Theorem 1 (i) If the Bėzier net $\mathrm{L}\left(\mathrm{f}_{\mathrm{n}} ; \mathrm{u}, \mathrm{v}, \mathrm{w}\right)$ is convex with respect to $\mathrm{T}$, so is the Bernstein polynomial $\mathrm{B}\left(\mathrm{f}_{\mathrm{n}} ; \mathrm{u}, \mathrm{v}, \mathrm{w}\right)$.

(ii) The Bèzier net $L\left(f_{n} ; u, v, w\right)$ is convex with respect to $T$ if and only if

$$
\left\{\begin{array}{l}
f_{i+2, j, k}+f_{i, j+1, k+1} \geq f_{i+1, j+1, k}+f_{i+1, j, k+1} \\
f_{i, j+2, k}+f_{i+1, j, k+1} \geq f_{i+1, j+1, k}+f_{i, j+1, k+1} \\
f_{i, j, k+2}+f_{i+1, j+1, k} \geq f_{i+1, j, k+1}+f_{i, j+1, k+1}
\end{array},\right.
$$

for $\mathrm{i}+\mathrm{j}+\mathrm{k}=\mathrm{n}-2$.

Using the shift operators, one may rewrite (8) as

$$
\left(E_{i_{1}}-E_{i_{2}}\right)\left(E_{i_{1}}-E_{i_{3}}\right) f_{i j k} \geq 0, i+j+k=n-2,
$$

for any permutation $\left\{i_{1}, i_{2}, i_{3}\right\}$ of $\{1,2,3\}$.

Let $\mathrm{V}_{1}^{*}, \mathrm{~V}_{2}^{*}$ and $\mathrm{V}_{3}^{*}$ be the vertices of another triangle $\mathrm{T}^{*}$ in the same plane as $\mathrm{T}$ and let

$$
\mathrm{P}=\mathrm{u}^{*} \mathrm{~V}_{1}^{*}+\mathrm{v}^{*} \mathrm{~V}_{2}^{*}+\mathrm{w}^{*} \mathrm{~V}_{3}^{*}, \mathrm{u}^{*}+\mathrm{v}^{*}+\mathrm{w}^{*}=1
$$

define the barycentric coordinates $\left(\mathrm{u}^{*}, \mathrm{v}^{*}, \mathrm{w}^{*}\right)$ of $\mathrm{P}$ with respect to $\mathrm{T}^{*}$. Assume that $\mathrm{V}_{\mathrm{i}}^{*}$ has barycentric coordinates $\left(\mathrm{u}_{\mathrm{i}}, \mathrm{v}_{\mathrm{i}}, \mathrm{w}_{\mathrm{i}}\right)$ with respect to $\mathrm{T}$, that is,

$$
\mathrm{V}_{\mathrm{i}}^{*}=\mathrm{u}_{\mathrm{i}} \mathrm{V}_{1}+\mathrm{v}_{\mathrm{i}} \mathrm{V}_{2}+\mathrm{w}_{\mathrm{i}} \mathrm{V}_{3}, \mathrm{u}_{\mathrm{i}}+\mathrm{v}_{\mathrm{i}}+\mathrm{w}_{\mathrm{i}}=1
$$

for $i=1,2,3$. Then

$$
\left\{\begin{array}{l}
u=u^{*} u_{1}+v^{*} u_{2}+w^{*} u_{3} \\
v=u^{*} v_{1}+v^{*} v_{2}+w^{*} v_{3} \\
w=u^{*} w_{1}+v^{*} w_{2}+w^{*} w_{3}
\end{array}\right.
$$

A Bernstein polynomial on $\mathrm{T}^{*}$ is defined symbolically by

$$
B\left(f_{n}^{*} ; u^{*}, v^{*}, w^{*}\right)=\left(u^{*} E_{1}^{*}+v^{*} E_{2}^{*}+w^{*} E_{3}^{*}\right)^{n} f_{000}^{*}
$$

Where

$$
f_{n}^{*}=\left\{f_{i j k}^{*} \in R \mid i+j+k=n, i \geq 0, j \geq 0, k \geq 0\right\}
$$

and $\mathrm{E}_{\mathrm{i}}^{*}$ define the shift operators on $\mathrm{T}^{*}$. We then have:

Theorem 2 (Chang and Davis[1]) Let

$$
\mathrm{f}_{\mathrm{ijk}}^{*}=\left(\mathrm{u}_{1} \mathrm{E}_{1}+\mathrm{v}_{1} \mathrm{E}_{2}+\mathrm{w}_{1} \mathrm{E}_{3}\right)^{\mathrm{i}}\left(\mathrm{u}_{2} \mathrm{E}_{1}+\mathrm{v}_{2} \mathrm{E}_{2}+\mathrm{w}_{2} \mathrm{E}_{3}\right)^{\mathrm{j}}\left(\mathrm{u}_{3} \mathrm{E}_{1}+\mathrm{v}_{3} \mathrm{E}_{2}+\mathrm{w}_{3} \mathrm{E}_{3}\right)^{\mathrm{k}} \mathrm{f}_{000},
$$


for $i+j+k=n$. Then $B\left(f_{n}^{*} ; u^{*}, v^{*}, w^{*}\right)$ is the Bernstein representation of $B(f ; u, v, w)$ with respect to

$\mathrm{T}^{*}$.

Proof: From (12) and (15) we obtain, by equating coefficients,

$$
\begin{aligned}
& B\left(f_{n} ; u, v, w\right)=\left(u E_{1}+v E_{2}+w_{3}\right)^{n} f_{000} \\
& \quad=\left[u^{*}\left(u_{1} E_{1}+v_{1} E_{2}+w_{1} E_{3}\right)+v^{*}\left(u_{2} E_{1}+v_{2} E_{2}+w_{2} E_{3}\right)+w^{*}\left(u_{3} E_{1}+v_{3} E_{2}+w_{3} E_{3}\right)\right]^{n} f_{000} \\
& =\left(u^{*} E_{1}^{*}+v^{*} E_{2}^{*}+w^{*} E_{3}^{*}\right)^{n} f_{000}^{*}
\end{aligned}
$$

if and only if

$$
\mathrm{E}_{1}^{* \mathrm{i}} \mathrm{E}_{2}^{* j^{*}} \mathrm{E}_{3}^{* \mathrm{k}} \mathrm{f}_{000}^{*}=\left(\mathrm{u}_{1} \mathrm{E}_{1}+\mathrm{v}_{1} \mathrm{E}_{2}+\mathrm{w}_{1} \mathrm{E}_{3}\right)^{\mathrm{i}}+\left(\mathrm{u}_{2} \mathrm{E}_{1}+\mathrm{v}_{2} \mathrm{E}_{2}+\mathrm{w}_{2} \mathrm{E}_{3}\right)^{\mathrm{j}}+\left(\mathrm{u}_{3} \mathrm{E}_{1}+\mathrm{v}_{3} \mathrm{E}_{2}+\mathrm{w}_{3} \mathrm{E}_{3}\right)^{\mathrm{k}} \mathrm{f}_{000}
$$

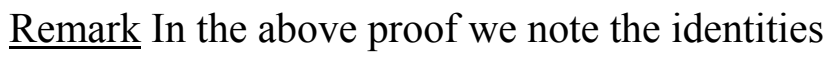

$$
\mathrm{E}_{\mathrm{i}}^{*}=\mathrm{u}_{\mathrm{i}} \mathrm{E}_{1}+\mathrm{v}_{\mathrm{i}} \mathrm{E}_{2}+\mathrm{w}_{\mathrm{i}} \mathrm{E}_{3}, \mathrm{i}=1,2,3,
$$

where, in symbolic manipulation involving theseoperators, indices in operator expressions must sum to $\mathrm{n}$ and the operator expressions are applied to $\mathrm{f}_{000}^{*}=\mathrm{f}_{000}$.

The set $f_{n}^{*}$ determines a new Bezier net $L\left(f_{n}^{*} ; u^{*}, v^{*}, w^{*}\right)$ which is a piecewise linear function on $\mathrm{T}^{*}$. We call $\mathrm{L}\left(\mathrm{f}_{\mathrm{n}}^{*}\right)$ the restricted Bezier net of $\mathrm{L}\left(\mathrm{f}_{\mathrm{n}}\right)$ on $\mathrm{T}^{*}$. Naturally, $\mathrm{T}^{*}$ is called a sub-triangle of $\mathrm{T}$ if $\mathrm{V}_{1}^{*}, \mathrm{~V}_{2}^{*}$ and $\mathrm{V}_{3}^{*}$, the vertices of $\mathrm{T}^{*}$ are all inside or on the boundary of $\mathrm{T}$. In this case $\mathrm{u}_{\mathrm{i},} \mathrm{v}_{\mathrm{i},} \mathrm{w}_{\mathrm{i}} \geq 0, \mathrm{i}=1,2,3$.

Let $\mathrm{T}^{*}$ be a sub-triangle of $\mathrm{T}$. Then if $\mathrm{B}\left(\mathrm{f}_{\mathrm{n}} ; \mathrm{u}, \mathrm{v}, \mathrm{w}\right)$ is convex with respect to $\mathrm{T}$, so is $\mathrm{B}\left(\mathrm{f}_{\mathrm{n}}^{*} ; \mathrm{u}^{*}, \mathrm{v}^{*}, \mathrm{w}^{*}\right)$ with respect to $\mathrm{T}^{*}$. One wouldask whether or not a similar result holds for the Bėzier nets. Grandine[4] showed a negative result but in [3], Goodman shows that if $\mathrm{T}^{*}$ is a sub-triangle obtained from a "mid-point" subdivision process, then the convexity of $\mathrm{L}\left(\mathrm{f}_{\mathrm{n}}\right)$ does guarantee the convexity of the restricted Beizier net $\mathrm{L}\left(\mathrm{f}_{\mathrm{n}}^{*}\right)$ with respect to $\mathrm{T}^{*}$. In the next section, we generalize this result and show that only a very limited class of sub-triangles have the property of preserving the convexity of Bėzier nets. 


\section{Main Result}

Let $\mathrm{T}^{*}$ be a non-degenerate triangle that lies on the plane determined by the base triangle T. We say $T^{*}$ is parallel to $T$ if each of the edges of $T^{*}$ is parallel to one of those of $T$. We now make the following definition:

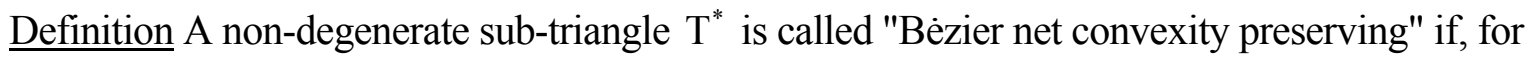
all Bėzier nets $L\left(f_{n}\right)$ that are convex with respect to $T$, the restricted Bėzier nets $L\left(f_{n}^{*}\right)$ on $T^{*}$ are also convex with respect to $\mathrm{T}^{*}$

Noting the barycentric coordinate representation of the vertices of $T^{*}$ with respect to $T$ in (11), we have the following lemma.

Lemma The following statements are equivalent,

(i) $\mathrm{T}^{*}$ is parallel to $\mathrm{T}$.

(ii) There exist a non-zero scalar $\rho$ and a permutation $\left\{i_{1}, i_{2}, i_{3}\right\}$ of $\{1,2,3\}$ such that

$$
\mathrm{V}_{\mathrm{i}_{1}}^{*}-\mathrm{V}_{\mathrm{i}_{2}}^{*}=\rho\left(\mathrm{V}_{1}-\mathrm{V}_{2}\right), \quad \mathrm{V}_{\mathrm{i}_{3}}^{*}-\mathrm{V}_{\mathrm{i}_{1}}^{*}=\rho\left(\mathrm{V}_{3}-\mathrm{V}_{1}\right), \quad \mathrm{V}_{\mathrm{i}_{2}}^{*}-\mathrm{V}_{\mathrm{i}_{3}}^{*}=\rho\left(\mathrm{V}_{2}-\mathrm{V}_{3}\right) .
$$

(iii) None of the sets $\left\{\mathrm{u}_{1}, \mathrm{u}_{2}, \mathrm{u}_{3}\right\},\left\{\mathrm{v}_{1}, \mathrm{v}_{2}, \mathrm{v}_{3}\right\}$ and $\left\{\mathrm{w}_{1}, \mathrm{w}_{2}, \mathrm{w}_{3}\right\}$ has all distinct members.
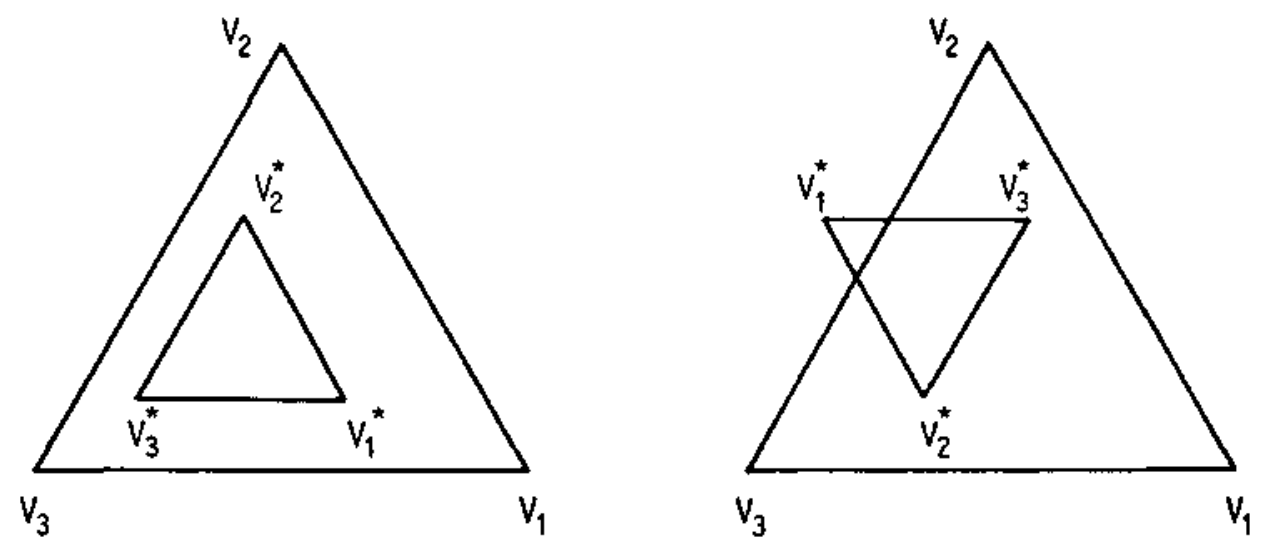

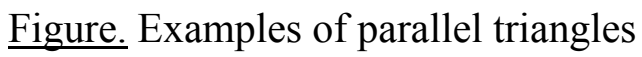

This lemma is illustrated by the two examples of parallel triangles labelled as shown in the $-5-$

figure. Property (ii) is simply a statement that the edges are parallel and property (iii) is a 
restatement of this property in terms of the barycentric coordinates of

$$
\mathrm{V}_{\mathrm{i}}^{*}=\mathrm{u}_{\mathrm{i}} \mathrm{V}_{1}+\mathrm{v}_{\mathrm{i}} \mathrm{V}_{2}+\mathrm{w}_{\mathrm{i}} \mathrm{V}_{3}, \quad \mathrm{i}=1,2,3
$$

Thus, in the examples $\mathrm{u}_{2}=\mathrm{u}_{3}, \mathrm{v}_{3}=\mathrm{v}_{1}$ and $\mathrm{w}_{1}=\mathrm{w}_{2}$.

We now present our main theorem:

Theorem 3 Let $\mathrm{T}^{*}$ be a non-degenerate sub-triangle of $\mathrm{T}$. Then $\mathrm{T}^{*}$ is Bézier net convexity preserving if and only if it is parallel to $\mathrm{T}$.

Proof: Suppose $T^{*}$ is parallel to $T$ and let $L\left(f_{n}\right)$ be any Bėzier net that is convex with respect to T. Comparing (16) and (11), it follows by statement (ii) of the lemma that there exist a non-zero scalar $\rho$ and a permutation $\left\{\mathrm{i}_{1}, \mathrm{i}_{2}, \mathrm{i}_{3}\right\}$ of $\{1,2,3\}$ such that

$$
\mathrm{E}_{\mathrm{i}_{1}}^{*}-\mathrm{E}_{\mathrm{i}_{2}}^{*}=\rho\left(\mathrm{E}_{1}-\mathrm{E}_{2}\right), \mathrm{E}_{\mathrm{i}_{3}}^{*}-\mathrm{E}_{\mathrm{i}_{1}}^{*}=\rho\left(\mathrm{E}_{3}-\mathrm{E}_{1}\right), \mathrm{E}_{\mathrm{i}_{2}}^{*}-\mathrm{E}_{\mathrm{i}_{3}}^{*}=\rho\left(\mathrm{E}_{2}-\mathrm{E}_{3}\right) .
$$

Thus, by (16), we have for $i+j+k=n-2$

$$
\begin{aligned}
&\left(E_{\mathrm{i}_{2}}^{*}-E_{\mathrm{i}_{2}}^{*}\right)\left(\mathrm{E}_{\mathrm{i}_{2}}^{*}-\mathrm{E}_{\mathrm{i}_{3}}^{*}\right) \mathrm{f}_{\mathrm{ijk}}^{*}=\mathrm{E}_{1}^{* i} \mathrm{E}_{2}^{* j} \mathrm{E}_{3}^{* \mathrm{k}}\left(\mathrm{E}_{\mathrm{i}_{2}}^{*}-\mathrm{E}_{\mathrm{i}_{3}}^{*}\right)\left(\mathrm{E}_{\mathrm{i}_{2}}^{*}-\mathrm{E}_{\mathrm{i}_{3}}^{*}\right) \mathrm{f}^{*} 000 \\
&= \rho^{2}\left(\mathrm{u}_{1} \mathrm{E}_{1}+\mathrm{v}_{1} \mathrm{E}_{2}+\mathrm{w}_{1} \mathrm{E}_{3}\right)^{\mathrm{i}}\left(\mathrm{u}_{2} \mathrm{E}_{1}+\mathrm{v}_{2} \mathrm{E}_{2}+\mathrm{w}_{2} \mathrm{E}_{3}\right)^{\mathrm{j}}\left(\mathrm{u}_{3} \mathrm{E}_{1}+\mathrm{v}_{3} \mathrm{E}_{2}+\mathrm{w}_{3} \mathrm{E}_{3}\right)^{\mathrm{k}}\left(\mathrm{E}_{1}-\mathrm{E}_{2}\right)\left(\mathrm{E}_{1}-\mathrm{E}_{3}\right) \mathrm{f}_{000} \\
&= \sum_{\mathrm{r}+\mathrm{s}+\mathrm{t}=\mathrm{i}} \sum_{\alpha+\beta+\mathrm{y}=1} \sum_{\lambda+\mu+\mathrm{v}=\mathrm{k}} \rho^{2} \mathrm{~B}_{\mathrm{rst}}^{\mathrm{i}}\left(\mathrm{u}_{1}, \mathrm{v}_{1}, \mathrm{w}_{1}\right) \mathrm{B}_{\alpha \beta \gamma}^{\mathrm{j}}\left(\mathrm{u}_{2}, \mathrm{v}_{2} \mathrm{w}_{2}\right) \mathrm{B}_{\lambda \mu v}^{\mathrm{k}}\left(\mathrm{u}_{3}, \mathrm{v}_{3}, \mathrm{w}_{3}\right) \\
& \quad\left(\mathrm{E}_{1}-\mathrm{E}_{2}\right)\left(\mathrm{E}_{1}-\mathrm{E}_{3}\right) \mathrm{f}_{\mathrm{r}+\alpha+\lambda, \delta+\beta+\mu, \mathrm{t}+\mathrm{y}+\mathrm{v}}
\end{aligned}
$$

$\geq 0$.

Similarly,

$$
\left(E_{\mathrm{i}_{2}}^{*}-\mathrm{E}_{\mathrm{i}_{1}}^{*}\right)\left(\mathrm{E}_{\mathrm{i}_{2}}^{*}-\mathrm{E}_{\mathrm{i}_{3}}^{*}\right) \mathrm{f}_{\mathrm{ijk}}^{*} \geq 0, \quad\left(\mathrm{E}_{\mathrm{i}_{3}}^{*}-\mathrm{E}_{\mathrm{i}_{1}}^{*}\right)\left(\mathrm{E}_{\mathrm{i}_{3}}^{*}-\mathrm{E}_{\mathrm{i}_{2}}^{*}\right) \mathrm{f}_{\mathrm{ijk}}^{*} \geq 0 .
$$

We therefore conclude that $\mathrm{L}\left(\mathrm{f}_{\mathrm{n}}^{*}\right)$ is convex with respect to $\mathrm{T}^{*}$.

We now suppose that $\mathrm{T}^{*}$. is not parallel to $\mathrm{T}$. By statement (iii) of the lemma, at least one of the sets $\left\{\mathrm{u}_{1}, \mathrm{u}_{2}, \mathrm{u}_{3}\right\},\left\{\mathrm{v}_{1}, \mathrm{v}_{2}, \mathrm{v}_{3}\right\}$ and $\left\{\mathrm{w}_{1}, \mathrm{w}_{2}, \mathrm{w}_{3}\right\}$ has all distinct members. Without loss of

generality, we assume $u_{2}>u_{1}>u_{3} \geq 0$. Then we have

$$
\left(\mathrm{u}_{1}-\mathrm{u}_{2}\right)\left(\mathrm{u}_{1}-\mathrm{u}_{3}\right)<0 .
$$

Consider the situation where 


$$
\mathrm{f}_{\mathrm{ijk}}=\delta_{\mathrm{i}, \mathrm{n}-1}, \quad \mathrm{i}+\mathrm{j}+\mathrm{k}=\mathrm{n},
$$

that is, $\mathrm{f}_{\mathrm{n}, 0,0}=1$ and $\mathrm{f}_{\mathrm{ijk}}=0$ if $\mathrm{i} \leq-1$. Obviously, the Bezier net $\mathrm{L}\left(\mathrm{f}_{\mathrm{n}}\right)$ defined by $(18)$ is convex with respect to T. Using (15) we obtain

$$
f_{i j k}^{*}=u_{1}^{i} u_{2}^{j} u_{3}^{k}, \quad i+j+k=n
$$

Hence for $\mathrm{i}+\mathrm{j}+\mathrm{k}=\mathrm{n}-2$ we have

$$
\left(E_{1}^{*}-E_{2}^{*}\right)\left(E_{1}^{*}-E_{3}^{*}\right) f_{i j k}^{*}=u_{i}^{i} u_{2}^{i} u_{3}^{k}\left(u_{1}-u_{2}\right)\left(u_{1}-u_{3}\right)
$$

and, particularly for $\mathrm{n} \geq 2$,

$$
\left(\mathrm{E}_{\mathrm{i}_{1}}^{*}-\mathrm{E}_{\mathrm{i}_{2}}^{*}\right)\left(\mathrm{E}_{\mathrm{i}_{1}}^{*}-\mathrm{E}_{\mathrm{i}_{3}}^{*}\right) \mathrm{f}_{0, \mathrm{n}-2,0}^{*}=\mathrm{u}_{2}^{\mathrm{n}-2}\left(\mathrm{u}_{1}-\mathrm{u}_{2}\right)\left(\mathrm{u}_{1}-\mathrm{u}_{3}\right)<0 .
$$

Thus the restricted Bèzier net $\mathrm{L}\left(\mathrm{f}_{\mathrm{n}}^{*}\right)$ is not convex with respect to $\mathrm{T}^{*}$.

Acknowledgements: This work was supported by the ACME Directorate of the Science and Engineering Research Council and by Siemens AG.

\section{References}

[1] Chang, G. and P.J.Davis(1984), The convexity of Bernstein polynomials over triangles, J. Approximation Theory 40, 11-28.

|2] Dahmen, W. and C.A.Micchelli(1985), Convexity of multivariate Bernstein olynomials and box spline surfaces, Research Report RC 11176, T.J.Watson Research Center.

[3] Goodman, T.N.T.(1989),Convexity of Bèzier nets on triangulations, AA/899, Department of Mathematics and Computer Science, University of Dundee.

[4] Grandine, T.A.(1989), On convexity of piecewise polynomial functions on triangulations,

Computer Aided Geometric Design 6, 181-187. 